Original Article

\title{
Impact of COVID-19 on mental health and health-related qual- ity of life of humanitarian and healthcare workers in low-in- come countries. The case of Eastern Africa.
}

\author{
Alexis Nizigiyimana ${ }^{1, *}$, and Thomas G. Poder ${ }^{2}$ \\ ${ }^{1}$ student in health policy, system and organization department at University of Montreal (UoM), Canada. \\ Email: alexis.nizigiyimana@umontreal.ca \\ 2 UoM, thomas.poder@umontreal.ca \\ *Correspondance : alexis.nizigiyimana@umontreal.ca; 3081Rue Racicot, Longueuil, QC, J4L 3J3.
}

Publisher's Note: MDPI stays neutral with regard to jurisdictional claims in published maps and institutional affiliations.

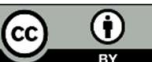

Copyright: $\odot 2021$ by the authors. Submitted for possible open access publication under the terms and conditions of the Creative Commons Attribution (CC BY) license (http://creativecommons.org/licenses/by/4.0/).

\begin{abstract}
BACKGROUND: The COVID-19 pandemic has had a direct impact on the health care system, adversely affecting services delivery and continuity, particularly in low-income countries. The overwhelming workload, the shortage of personal protective equipment, and the lack of specific Personal protective equipment (PPE), and drugs are some noted challenges. As a result of this critical situation, healthcare and humanitarian workers who are directly involved in the diagnosis, management, and prevention of COVID-19 are at high risk of contracting COVID-19 disease and developing psychological disorders, distress, and other mental health symptoms. OBJECTIVE: To assess the magnitude of mental health and health-related quality of life (HRQoL) outcomes and associated factors among humanitarian and healthcare workers (HCW) working on prevention and management of COVID-19 in East African Countries (EAC). DESIGN, SETTINGS, AND PARTICIPANTS: This cross-sectional, online-based survey study collected socio-demographic, mental health, and HRQoL data from 739 frontline and second-line workers in healthcare facilities and humanitarian NGOs working on COVID-19 prevention and management in seven Eastern African countries (Burundi, Kenya, Tanzania, South Sudan, Somalia, Ethiopia, and Rwanda). MAIN OUTCOMES AND MEASURES: The degree of symptoms of depression, anxiety, insomnia, and distress, alcohol, and tobacco consumption, HRQoL (SF-6Dv2 and CORE-6D), and fear of COVID-19. ANALYSIS: Multivariable logistic regression analysis, one-way ANOVA, and T-test to identify factors associated with mental health and HRQoL outcomes. RESULTS: A total of 739 contacted individuals in December 2020 completed the survey. The study participants included $62.7 \%$ of males and $37.3 \%$ of females. Among them, $12.4 \%$ were humanitarians and $87.6 \%$ were healthcare workers. About $83 \%$ were from Burundi and 17\% from other Eastern African countries. The HRQoL mean scores measured by the SF-6Dv2 and the CORE-6D were respectively 0.86 and 0.80 . Multivariable logistic regression analysis showed that country of origin, chronic disease, being tested positively to COVID-19, being exposed to death due to COVID-19, increased alcohol uptake, having experienced nightmare, insomnia, distress, stress, and fear of COVID-19 were independent predictors of HRQoL of front- and second-line workers. Multivariable Logistic Regression Analysis also found that having a chronic disease, being exposed to patients and death due to COVID-19 cases, depression, insomnia, stress, and fear of COVID-19 were independent predictors of the CORE-6D score. CONCLUSION: This study showed that healthcare and humanitarian workers are affected by mental health disorders such as depression, anxiety, stress, and insomnia, which negatively impacted their Health-related quality of life (HRQoL). The study findings suggested that psychological support to ensure humanitarian and healthcare worker's safety and wellbeing is required during and after this pandemic.
\end{abstract}

Keywords: COVID-19; Mental health; HRQoL; HCW and Humanitarian workers; EAC. 


\section{INTRODUCTION}

December 31, 2019, China has reported the first COVID-19 case in Wuhan city, which has subsequently spread around the world(1). According to the latest report by World Health Organization (WHO), this disease has spread in 220 countries around the world accounting for 83322449 Confirmed cases, and 1831412 Confirmed deaths (WHO,2021). Since the beginning of the pandemic, the virus has rapidly spread across the African region, and according to the latest report by WHO Afro, eastern African countries have seen a slight increase in cases and deaths compared to the developed countries (WHO,2021). Globally, as millions of people stay at home to minimize transmission of COVID-19, health-care workers prepare to do the exact opposite as they go to clinics and hospitals, putting themselves at high risk from COVID-2019(2). A previous study showed that show that more than 3300 health-care workers have been infected as of early March, and by the end of February at least 22 had died in China, and $20 \%$ of responding health-care workers were infected in Italy (2).

As a result of this critical situation, front-line health and humanitarian workers who are directly involved in the diagnosis, management, and prevention of COVID-19 are at high risk of contracting COVID-19 disease and developing psychological disorders, distress, and other mental health symptoms. A large study with a probabilistic sampling of the UK population indicated that comparing before and during the lockdown, there was an increase in the overall mental distress, with the prevalence of clinical levels reaching 27.3\% of the participants(3). A cross-sectional study conducted in Vietnam in March 2020, showed a moderate rate of psychological distress and lower HRQoL outcomes among frontline HCWs during the COVID-19 outbreak in Vietnam(4). the same study was reported in Italy and China(1,5). little information is known on the impact of COVID-19 on health-related quality of life and mental health of frontline and second-line workers in Eastern African Countries (EAC), hence we conduct this study.

\section{METHOD}

\section{DESIGN}

This cross-sectional, web-based study collected data between December $1^{\text {st }}$ to December $20^{\text {th }}, 2020$, using an online questionnaire spread via social media to humanitarian and health care workers living in Burundi, Rwanda, Tanzania, Somalia, South Sudan, Kenya, and Ethiopia. Because of the self-selected and nonprobabilistic nature of the sample, invitations and response rates was not quantifiable, as reported by the American Association for Public Opinion Research (AAPOR) reporting guideline(6). The questionnaire investigated demographic variables, workplace characteristics (ie, being a frontline or secondline worker), and information regarding the direct consequences of COVID-19, including having contacts with patients or family members infected or deceased. Frontline and second-line HCWs were defined by a single yes or no question, "Are you currently working on frontline or second-line with COVID-19 patients?" Frontline workers were those directly involved in treating, testing COVID-19, while second-line workers were those who were indirectly involved in treating, preventing COVID-19 in communities or health facilities. Key mental health outcomes were the degree of symptoms of depression, anxiety, insomnia, and distress, and health-related quality of life, assessed by a Short-form SixDimension (SF-6Dv2) (7) health index designed for calculating Quality Adjusted Life Years (QALYs), and a Clinical Outcomes in Routine Evaluation-Outcome Measure (CORE_OM) (8), and Fear of COVID-19 scale(9).the completion of the questionnaire was estimated to take approximately 15 minutes.

\section{ETHICAL CONSIDERATIONS}

An online consent was obtained from the participants. Participants were free to refuse to participate in the research without having to justify themselves. Failure to answer 
the questionnaire on his part was considered as an objection, and the fact of answering the questionnaire act as his consent. Participation in the study was of course free, anonymous, and confidential.

\section{SETTINGS, AND PARTICIPANTS}

This cross-sectional, online-based survey study collected socio-demographic, mental health, and HRQoL data from frontline and second-line workers in healthcare facilities and humanitarian NGOs working on COVID-19 prevention and management in seven EAC (Burundi, Kenya, Tanzania, South Sudan, Somalia, Ethiopia, and Rwanda). The population eligible to participate were humanitarian and health care workers working on frontline and second-line of COVID-19 response in EAC.

\section{Statistical Analysis}

Data was collected in Excel and imported into SPSS version 15.0. Descriptive statistics were performed to summarize the frequency of demographic, socio-economic, and clinical factors and outcomes. One-way ANOVA, T-test, univariate analysis, and multivariable logistic regression were performed to examine the association between variables and selected outcomes. Logistic regression was used to obtain the crude and the adjusted correlation with $95 \%$ confidence intervals(95\%CIs) between HRQoL and associated factors, with adjustment for potential confounders. The interactions were tested by the BreslowDay Chi-square test and logistic regression.

\section{RESULTS}

Descriptive analysis.

In this study, 739 participants completed the survey. As showed in table 1.A(Appendice A), of 739 participants, $62.7 \%$ were males and $37.3 \%$ were females. $12.4 \%$ were humanitarians and $87.6 \%$ were health care providers (out of them, $36.3 \%$ were medical doctors, $23.3 \%$ of the nurse, $19.1 \%$ of medical interns, $3.8 \%$ of social workers, $5.1 \%$ of lab technicians). Most participants were from Burundi representing $83 \%$ vs. $17 \%$ from other seven EAC (out of them, 8.6\% were Kenyans,3.1\% were Rwandans, 0,7\% were Somalians, 2.3\% were south Sudanese, $1.9 \%$ were Ethiopians, and $0.4 \%$ were Tanzanians). The majority of respondents were aged above 30 years old. The marriage status was similar among respondents $50.1 \%$ vs. $49.9 \%$ of married. out of total respondents, $89.5 \%$ were from urban areas while $10.9 \%$ live work in rural areas. The clinical characteristics of participants are presented in Table 2. As seen in table 2.A.(Appendice A), 33.4\% of them express depression symptoms, $24.3 \%$ experienced insomnia, $44.1 \%$ were stressed out, and $33 \%$ were distressed. $4.2 \%$ were tested positive, $19.1 \%$ have been suspected of COVID-19, 17.5\% have been quarantined, 30.9\%were exposed to COVID-19 patients in the hospital while $7.4 \%$ were exposed to a family member suffering from covid-19, $4.0 \%$ have been exposed to death from COVID-19, most participants (53.2\%) experienced shortage of PPE, and 30.4 $\%$ lack of medicines. As showed in table2, 28.4\% increased alcohol consumption and $4 \%$ increased smoking.

Logistic regression analysis

Univariate analysis

The mean QALY SF-6Dv2 was .86 \pm .182 , The mean CORE6D was $.80 \pm .143$, and the mean Fear of COVID-19 was 19.23 \pm 6.42 . Females had a lower HRQoL score compared to males ( $0.85 \mathrm{vs} 0.87)$ but it was not statistically significant $(\mathrm{p}=0.093)$. The results of univariate analysis for the association between socio-demographic factors and the mean QALY SF6Dv2 are presented in table 3.B (Appendice B). The difference between the mean QALY SF-6Dv2 was statistically significant for Age $(p<0.001)$, marriage status $(p=0.026)$, education level $(p=0.003)$, Country of origin $(p<0.001)$, and monthly income $(p=0.017)$. old and 
single HCW and humanitarian had lower HRQoL scores compared to their counterpart $(\mathrm{p}<0.005)$.

The association between clinical factors and QALY SF-6Dv2 are shown in table 4.B(Appendice B). The difference between clinical factors and the mean QALY SF-6Dv2 was statistically significant for Worker with chronic disease $(\mathrm{p}=0.002)$, positively tested of COVID-19( $\mathrm{p}<0.001)$, been suspected of covid-19 $(\mathrm{p}<0.001)$, been quarantined $(\mathrm{p}<0.001)$, exposed to COVID-19 in hospital and family $(\mathrm{p}<0.001)$, exposed to death $(\mathrm{p}=0.026)$, shortage of PPE \&drugs $(\mathrm{p}<0.001)$, having called a physician $(\mathrm{p}=0.001)$ and experienced traumatic memories $(\mathrm{p}<0.001$, and smoking status $(\mathrm{p}<0.001)$.

Multivariate analysis.

As showed in table 5.B(Appendice B), the factors associated with HRQoL scores using the multivariable Logistic Regression Analysis showed that country of origin, chronic disease, being tested positively COVID, being exposed to death due to COVID-19, increased alcohol uptake, having experienced nightmare, insomnia, distress, stress, and fear have a significant negative effect on the SF-6Dv2 score $(\mathrm{p}<0.05)$ among frontline and second-line workers.

As seen in Table 6.B (Appendice B), the factors associated with HRQoL scores using multivariable Logistic Regression Analysis found that having a chronic disease, being exposed to patients and death due to COVID-19 cases, depression, insomnia, and stress and fear of COVID-19 have a significant negative effect on CORE_OM score $(\mathrm{p}<0.05)$.

As reported in figure 1: study results found a strong interaction between gender and country of origin in relation to anxiety and depression. Among the male, the odds of being anxious was 3.2 times higher among humanitarians and health care provider working in other ester African countries compared to those working in Burundi. For female, on the other hand, compared to their counterparts in Burundi, the odds of being anxious was 8.8 times higher among female humanitarians and health care works in other eastern African countries. The same interaction was found for depression as shown in figure 2.

Figure 1. Interaction between Gender and country of origin in relation to Anxiety.

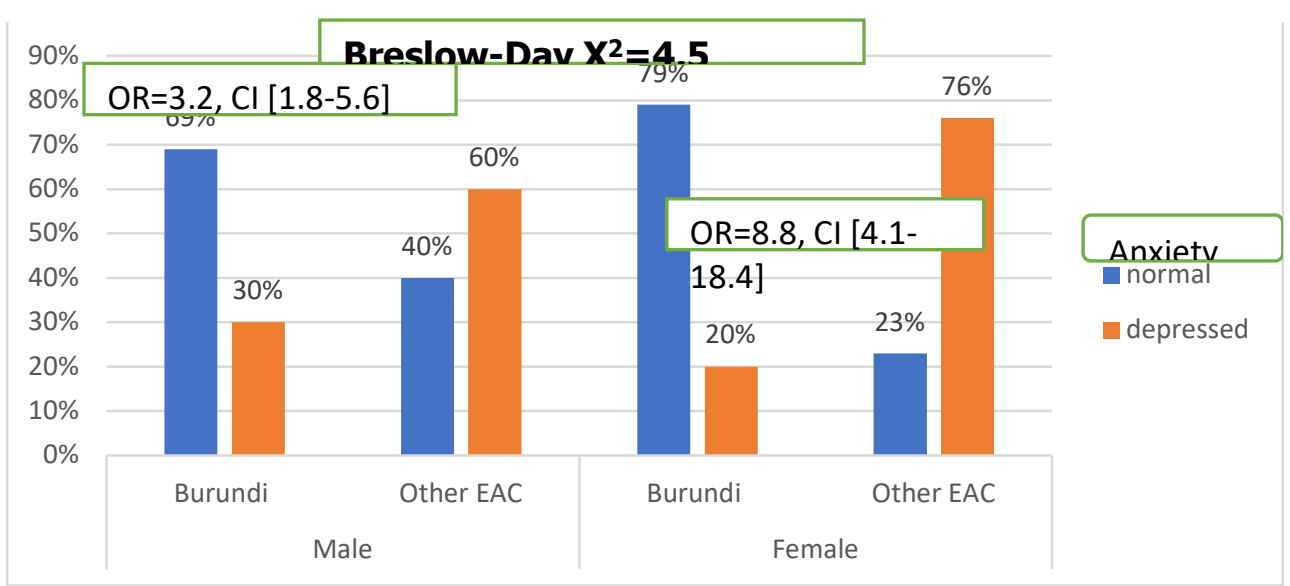

Figure 2: Interaction effect of gender and Country of origin in relation to depression 


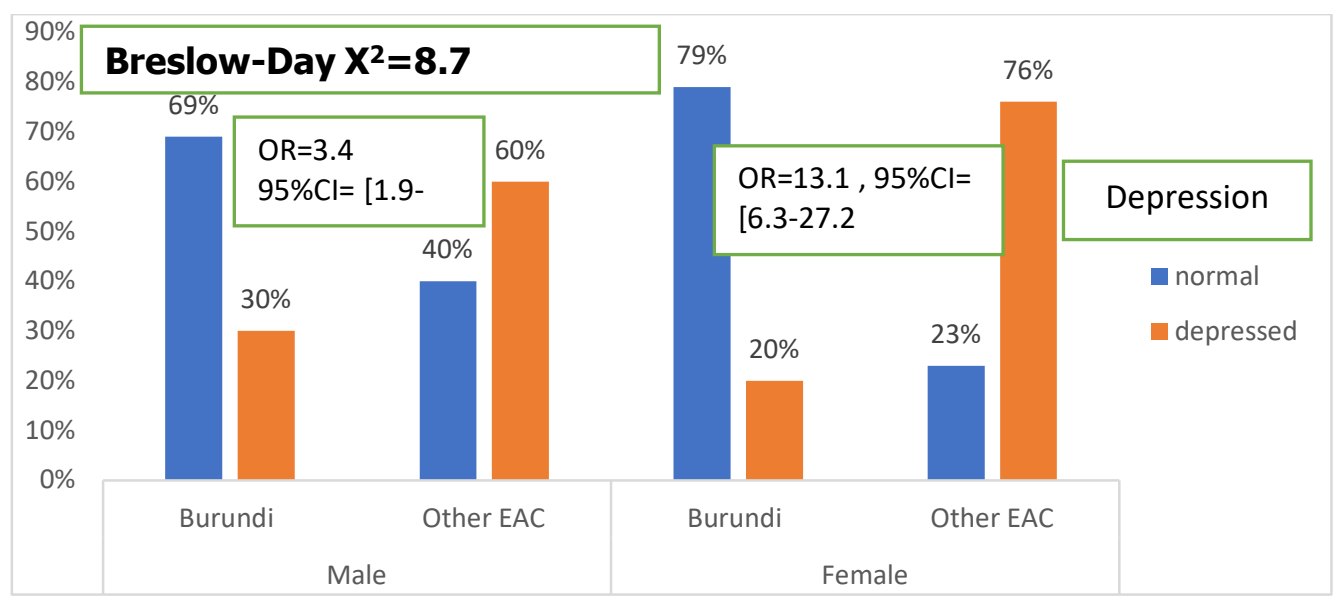

\section{DISCUSSION}

This study evaluated HRQoL and mental health problems of humanitarians and health care providers working on the frontline and second line of COVID-19 response using the SF-6Dv2, CORE6D, and Fear of COVID-19 questionnaire and examine the effects of sociodemographic and clinical factors associated with HRQoL. Health care workers are at high risk of contracting COVID-19 and face intensive pressure in treating, diagnosing patients suffering from covid-19, while humanitarian is working hard to slow the spread of the virus in the communities. this can lead to excessive fatigue and tension which led to anxiety, sadness, grievance, helplessness, and depression, among other emotions(10). Our study results showed $33.4 \%$ of respondents felt depressed, $24.3 \%$ experienced insomnia, $44.1 \%$ were stressed out, and $33 \%$ were distressed. Our results showed a strong interaction between gender and country of origin in relation to depression and anxiety, being a female working in other EAC was more likely associated with depression and anxiety than Burundian counterparts. We hypothesize that this difference is due to more cases in these EAC than in Burundi (WHO,2021). Overall, our results demonstrated a slightly lower rate of depression, insomnia, and distress among HCW and humanitarians when compared to other findings from China (1), but higher when compared to reports from Italy and Vietnam $(4,5)$. This difference may be due to more cases and strict preventive measures in China than EAC. Our findings showed a higher degree of depression and anxiety across all eastern African countries in general but women working in Burundi were less likely to be depressed and anxious compared to other eastern African countries. This difference can be explained by the fact that Burundi had not only less COVID-19 cases and deaths compared to other EAC, but also societal responses to COVID-19 were different worldwide(11). Similar results were found in China and Italy and Vietnam $(4,5,10)$. Out of our respondents, the mean QALY-SF-6Dv2 score was $0.86 \pm 0.182$, which was higher than what was found in China and lower than what was found in Vietnam(4). This difference is related to the fact that China had more covid-19 cases and deaths than EAC as well as Vietnam. Burundi has a higher QALY-SF-6Dv2 score (0.89) than other EAC (0.74). This can be explained by the fact that Burundi has few COVID-19 cases and has not applied lockdown compared to other EAC. Mixed results were found on the HQRoL score related to change of alcohol and smoking consumptions as follows: the HQRoL score was lower among smokers who increased cigarette uptake (0.79) compared to those who did not change (0.87) and those who decreased (0.94). the same results were found with alcohol consumption. Our findings demonstrated that increasing both smoking and alcohol consumption reduced HRQoL while decreasing were associated with higher HRQoL. Similar results were found in Australia and Netherland, where smoking and alcohol consumption were associated with stress, which may consequently deteriorate the $\operatorname{HQoL}(12,13)$. Multivariate analysis showed that the socio-demographic 
characteristics associated with HRQoL of the respondents were gender, occupation, country of origin, and living with chronic disease. Females were associated with a lower QALY-SF-6Dv2 score compared to males. A QALY-SF-6Dv2 score of respondents living in other EAC was worse, which may be related to the more serious epidemic situation, strict societal preventive measures, and higher risk of infection among frontline and second-line workers compared to Burundi. The multivariate analysis also showed that the mental health problems were associated with lower HRQoL (QALY-SF-6Dv2) score as follows: being Destressed (0.77), being stressed (0.82), having insomnia (0.73), being depressed (0.77), having increased smoking (0.79). The analysis also revealed that a low HRQ0L score was associated with having the chronic disease (0.79), been tested positive for COVID-19 (0.74), been exposed to death (0.70), been expressed nightmare (0.75), and having fear of COVID-19. These results demonstrated that mental health was the main contributor to the reduction of HQRoL among our participants during the COVID-19 pandemic. The same findings were found in other reports from China, Vietnam, and Italy $(4,5,10)$. The fear of being infected by COVID-19 was negatively associated with the HQRoL score. The higher the possibility of infection, the more likely professionals are to suffer from anxiety (4). These findings suggest that health institutions and organizations could prioritize the safety of health care and humanitarian workers through psychological interventions during and after the pandemic.

\section{LIMITATIONS}

There are limitations to this study that require further research work. As the study used an online questionnaire, there might be selection and information bias due to languages or cultural differences. The response rate was higher in Burundi and lower in other EAC which may cause bias in the comparison of results across the EAC region. Also, the survey was done while the COVID-19 vaccine was announced and COVID-19 management and prevention enhanced across the globe by easing the lockdown and social gathering which should alleviate the burden of psychological distress of COVID-19 and improve the health status of workers. Despite these limitations, the strength of this study has to be recognized as we used commonly used and validated SF-6Dv2, CORE6D, and Fear of COVID-19 questionnaire in collecting data. Also, the questionnaire was translated into both French and English language to increase the understanding of questions for our participants.

\section{CONCLUSION:}

The study showed a high level of psychological distress and a moderate level of HRQoL outcome among humanitarian and health care workers in EAC during the COVID-19 pandemic from December $1^{\text {st }}$ to December $20^{\text {th }}, 2020$. Both humanitarian and health care workers in Kenya, Rwanda, Ethiopia, Somalia, and South Sudan had a significantly higher psychological burden and lower HRQoL score than their Burundian counterparts. mental health problems and clinical aspects were the main contributor's factors to the reduction of HRQoL among study participants. Therefore, this study suggested that COVID-19 protection and mental health interventions would improve the health status and wellbeing of HCW and humanitarians. Also, this study findings will be useful for public health policymakers, health facility and NGO managers to increase the wellbeing of HCW and humanitarians during and after the pandemic.

CONFLICT OF INTEREST: The authors have no conflicts to declare.

FUNDING/SUPPORT: This study has received no external findings.

ACKNOWLEDGEMENTS: We would like to thank all humanitarians and health care workers who agreed to participate. Many thanks to Pr. Francois Ndikumwenayo, and others who have contributed in data collection across EAC. 


\section{APPADENCES}

\section{Appendice A}

Table 1. A: Participants Socio-Demographic Characteristics.

\begin{tabular}{|c|c|c|c|c|c|}
\hline Variable & Frequency & Percentage & Mean QALY & Mean CORE & Mean Fear-Covid-19 \\
\hline \multicolumn{6}{|l|}{ Gender } \\
\hline Male & 463 & 62.7 & .87 & .81 & 18.98 \\
\hline Female & 276 & 37.3 & .85 & .79 & 19.68 \\
\hline \multicolumn{6}{|l|}{ Age } \\
\hline $18-24$ & 75 & 10.1 & .90 & .81 & 19.56 \\
\hline $25-29$ & 259 & 34.9 & .89 & .82 & 18.90 \\
\hline $30-34$ & 143 & 19.3 & .84 & .78 & 18.48 \\
\hline $35-39$ & 150 & 20.2 & .84 & .78 & 19.57 \\
\hline $40-44$ & 60 & 8.1 & .86 & .79 & 19.66 \\
\hline $45-49$ & 31 & 4.2 & .80 & .76 & 21.19 \\
\hline$>50$ & 24 & 3.2 & .85 & .81 & 20.65 \\
\hline \multicolumn{6}{|l|}{ Marriage status } \\
\hline Unmarried & 371 & 50.3 & .88 & .82 & 18.66 \\
\hline Married & 366 & 49.7 & .85 & .78 & 19.76 \\
\hline \multicolumn{6}{|l|}{ Education level } \\
\hline $\begin{array}{c}\text { 1st secondary school level (6th to 9th } \\
\text { grade) }\end{array}$ & 2 & .3 & .97 & .87 & 19.50 \\
\hline $\begin{array}{l}\text { 2nd secondary school level (10th to 13th } \\
\text { grade) }\end{array}$ & 62 & 8.4 & .91 & .79 & 21.22 \\
\hline Bachelor degree & 303 & 41.1 & .85 & .79 & 20.11 \\
\hline Master degree & 97 & 13.1 & .83 & .79 & 18.74 \\
\hline Doctorate & 274 & 37.1 & .88 & .81 & 18.10 \\
\hline \multicolumn{6}{|l|}{ Residence } \\
\hline Rural & 77 & 10.5 & .83 & .76 & 19.90 \\
\hline Urban & 654 & 89.5 & .87 & .80 & 19.13 \\
\hline \multicolumn{6}{|l|}{ Country of origin } \\
\hline Burundi & 616 & 83.0 & .89 & .81 & 19.11 \\
\hline Kenya & 64 & 8.6 & .69 & .73 & 22.09 \\
\hline Rwanda & 23 & 3.1 & .86 & .81 & 13.96 \\
\hline Somalia & 5 & .7 & .67 & .68 & 19.20 \\
\hline South Sudan & 17 & 2.3 & .77 & .76 & 20.41 \\
\hline Ethiopia & 14 & 1.9 & .76 & .74 & 19.14 \\
\hline Tanzania & 3 & .4 & .87 & .83 & 18.00 \\
\hline \multicolumn{6}{|l|}{ Country of origin } \\
\hline Burundi & 614 & 83.4 & & & \\
\hline Other Eastern African countries & 123 & 16.6 & & & \\
\hline Tanzania & 3 & .4 & & & \\
\hline \multicolumn{6}{|l|}{ Type of occupation } \\
\hline Humanitarian & 92 & 12.4 & .86 & .80 & 20.46 \\
\hline Medical Doctor & 268 & 36.3 & .84 & .79 & 18.23 \\
\hline
\end{tabular}




\begin{tabular}{cccccc}
\hline Medical Intern & 141 & 19.1 & .91 & .85 & 17.45 \\
\hline Nurse & 172 & 23.3 & .86 & .78 & 20.83 \\
\hline Social worker & 28 & 3.8 & .82 & .77 & 22.26 \\
\hline Labo Technician & 38 & 5.1 & .94 & .82 & 20.94 \\
\hline Occupation & & & & & \\
\hline Humanitarian & 92 & 12.4 & & & \\
\hline health care worker & 643 & 87.6 & & & \\
\hline
\end{tabular}

\section{Monthly Income range (USD dollar)}

\begin{tabular}{cccccc}
\hline$<100$ & 120 & 17.7 & .902 & .85 & 17.80 \\
\hline $100-190$ & 219 & 32.3 & .87 & .79 & 20.06 \\
\hline $200-290$ & 68 & 10.0 & .88 & .81 & 18.76 \\
\hline $300-390$ & 35 & 5.2 & .82 & .74 & 18.62 \\
\hline $400-490$ & 32 & 4.7 & .88 & .80 & 17.03 \\
\hline $500-1000$ & 123 & 18.1 & .86 & .81 & 18.84 \\
\hline$>1000$ & 82 & 12.1 & .79 & .77 & 20.04 \\
\hline Working position & & & & & \\
\hline Second line & 145 & 20.0 & .87 & .79 & 19.37 \\
\hline Frontline & 581 & 80.0 & .86 & .80 & 19.27 \\
\hline
\end{tabular}

Table 2. A: Clinical Characteristics of participants.

\begin{tabular}{|c|c|c|c|c|c|}
\hline Variables & Frequency & Percentage & Mean QALY & $\begin{array}{l}\text { Mean } \\
\text { CORE }\end{array}$ & Mean Fear-Covid-19 \\
\hline \multicolumn{6}{|c|}{ Comorbidities } \\
\hline None & 445 & 84.1 & .86 & .81 & 19.13 \\
\hline Hypertension & 15 & 2.8 & .84 & .77 & 19.43 \\
\hline Diabetes & 10 & 1.9 & .75 & .74 & 17.40 \\
\hline Asthma & 2 & .4 & .96 & .76 & 15.00 \\
\hline Other & 57 & 10.8 & .81 & .75 & 19.79 \\
\hline \multicolumn{6}{|c|}{ Pregnant women } \\
\hline No & 685 & \begin{tabular}{|l|}
97.6 \\
\end{tabular} & .86 & .80 & 19.43 \\
\hline Yes & 17 & 2.4 & .82 & .77 & 17.18 \\
\hline \multicolumn{6}{|c|}{$\begin{array}{l}\text { Women with chil- } \\
\text { dren }\end{array}$} \\
\hline No & 411 & \begin{tabular}{|l|}
55.9 \\
\end{tabular} & .87 & .81 & 18.91 \\
\hline Yes & 324 & \begin{tabular}{|l|l|}
44.1 \\
\end{tabular} & .85 & .78 & 19.67 \\
\hline \multicolumn{6}{|c|}{$\begin{array}{l}\text { Positively tested } \\
\text { COVID }\end{array}$} \\
\hline No & 710(95.8) & \begin{tabular}{|l|}
95.8 \\
\end{tabular} & .87 & .80 & 19.16 \\
\hline Yes & $31(4.2)$ & \begin{tabular}{|l|}
4.2 \\
\end{tabular} & .74 & .69 & 21.00 \\
\hline \multicolumn{6}{|c|}{$\begin{array}{c}\text { Been suspected of } \\
\text { COVID-19 }\end{array}$} \\
\hline No & 599(80.9) & \begin{tabular}{|l|}
80.9 \\
\end{tabular} & .89 & .81 & 18.98 \\
\hline Yes & 141(19.1) & \begin{tabular}{|l|}
19.1 \\
\end{tabular} & .76 & .74 & 20.21 \\
\hline \multicolumn{6}{|c|}{ Been in quarantine } \\
\hline No & $610(82,5)$ & \begin{tabular}{|l|}
82.5 \\
\end{tabular} & .89 & .81 & 19.04 \\
\hline Yes & $129(17.5)$ & \begin{tabular}{|l|}
17.5 \\
\end{tabular} & .76 & .74 & 20.13 \\
\hline \multicolumn{6}{|c|}{$\begin{array}{l}\text { Exposed } \\
\text { COVID-19 pa- } \\
\text { tients in the } \\
\text { hospital }\end{array}$} \\
\hline No & $511(69.1)$ & 69.1 & .89 & .82 & 19.44 \\
\hline
\end{tabular}




\begin{tabular}{|c|c|c|c|c|c|}
\hline Yes & $228(30.9)$ & 30.9 & .80 & .75 & 18.86 \\
\hline \multicolumn{6}{|l|}{$\begin{array}{l}\text { Exposed to } \\
\text { COVID-19 pa- } \\
\text { tients in fam- } \\
\text { ily }\end{array}$} \\
\hline No & $687(92.6)$ & 92.6 & .87 & .81 & 19.15 \\
\hline Yes & $55(7.4)$ & 7.4 & .76 & .73 & 20.28 \\
\hline \multicolumn{6}{|l|}{$\begin{array}{l}\text { Those exposed to } \\
\text { death from } \\
\text { Covid-19 }\end{array}$} \\
\hline No & $711(96.0)$ & 96.0 & .87 & .81 & 19.11 \\
\hline Yes & $30(4.0)$ & 4.0 & .70 & .67 & 21.83 \\
\hline \multicolumn{6}{|l|}{ Shortage of PPE } \\
\hline No & $347(46.8)$ & 46.8 & .90 & .82 & 19.09 \\
\hline Yes & $395(53.2)$ & 53.2 & .83 & .78 & 19.36 \\
\hline \multicolumn{6}{|l|}{$\begin{array}{l}\text { Shortage of Medi- } \\
\text { cine }\end{array}$} \\
\hline No & $516(69.6)$ & 69.6 & .89 & .82 & 18.98 \\
\hline Yes & $225(30.4)$ & 30.4 & .80 & .77 & 19.80 \\
\hline \multicolumn{6}{|l|}{$\begin{array}{l}\text { Have you called a } \\
\text { physician }\end{array}$} \\
\hline No & & & .88 & .81 & 19.04 \\
\hline Yes & & & .74 & .74 & 21.98 \\
\hline \multicolumn{6}{|l|}{$\begin{array}{l}\text { Have you been trau- } \\
\text { matic memo- } \\
\text { ries }\end{array}$} \\
\hline No & & & .90 & .82 & 18.54 \\
\hline Yes & & & .75 & .73 & 21.95 \\
\hline \multicolumn{6}{|l|}{$\begin{array}{l}\text { Change in alcohol } \\
\text { drinking }\end{array}$} \\
\hline do not drink & 363 & 49.1 & .87 & .81 & 18.74 \\
\hline not at all & 116 & 15.7 & .90 & .82 & 19.40 \\
\hline Moderate increase & 203 & 27.5 & .87 & .80 & 19.50 \\
\hline Significant increase & 9 & 1.2 & .63 & .68 & 21.67 \\
\hline Moderate decrease & 28 & 3.8 & .80 & .78 & 21.71 \\
\hline Significant decrease & 20 & 2.7 & .77 & .75 & 19.45 \\
\hline \multicolumn{6}{|l|}{$\begin{array}{l}\text { Change in smoking } \\
\text { status }\end{array}$} \\
\hline Do not smoke & 671 & 90.7 & .87 & .80 & 19.24 \\
\hline No & 29 & 3.9 & .91 & .83 & 17.76 \\
\hline Moderate increase & 35 & 4.7 & .83 & .78 & 20.34 \\
\hline Significant increase & 2 & .3 & .26 & .48 & 25.50 \\
\hline Moderate decrease & 1 & .1 & 1.00 & .95 & 11.00 \\
\hline Significant decrease & 2 & .3 & .92 & .87 & 14.50 \\
\hline \multicolumn{6}{|l|}{$\begin{array}{c}\text { Insomnia } \\
\text { toms }\end{array}$ symp- } \\
\hline Normal & 553 & & .91 & .83 & 18.33 \\
\hline Mild & 127 & & .78 & .74 & 20.90 \\
\hline Moderate & 38 & & .67 & .68 & 23.87 \\
\hline Severe & 14 & & .50 & .59 & 26.64 \\
\hline \multicolumn{6}{|l|}{$\begin{array}{l}\text { Depression symp- } \\
\text { toms }\end{array}$} \\
\hline Normal & 476 & & .91 & .85 & 18.30 \\
\hline Mild & 175 & & .82 & .77 & 20.60 \\
\hline
\end{tabular}




\begin{tabular}{|l|l|l|l|l|l|}
\hline Moderate & 57 & & .70 & .70 & 22.45 \\
\hline Severe & 9 & & .36 & .52 & 26.44 \\
\hline Distress symptoms & & & & & \\
\hline Normal & 492 & & .91 & .83 & 18.25 \\
\hline Mild & 166 & & .82 & .78 & 20.43 \\
\hline Moderate & 61 & & .66 & .65 & 22.30 \\
\hline Severe & 15 & & .55 & .62 & 25.00 \\
\hline Anxiety & & & & \\
\hline Normal & 414 & 55.9 & .91 & .83 & 18.01 \\
\hline Mild & 207 & 28.0 & .85 & .79 & 19.98 \\
\hline Moderate & 102 & 13.8 & .75 & .72 & 21.57 \\
\hline Severe & 17 & 2.3 & .55 & .58 & 25.41 \\
\hline
\end{tabular}

\section{Appendice B}

Table 3. B: sociodemographic risk factors associated with Mean SF6DV identified by univariate analysis among frontline and second-line workers.

\begin{tabular}{|c|c|c|c|c|c|}
\hline Variable & $\mathbf{N}(\%)$ & Mean SF6DV & $\mathbf{t}$ & P-value & $95 \% \mathrm{CI}$ \\
\hline Gender & & & 1.68 & 0.093 & $0.003-0.05$ \\
\hline Male & $463(62.7)$ & .87 & & & \\
\hline Female & $276(37.3)$ & .85 & & & \\
\hline Age & & & 3.54 & .000 & $.01-.02$ \\
\hline $18-29$ & $331(45.0)$ & .89 & & & \\
\hline $30-50+$ & $406(55.0)$ & .84 & & & \\
\hline Marriage status & & & 2.2 & .026 & $.003-.05$ \\
\hline Unmarried & $367(50.1)$ & .88 & & & \\
\hline Married & $365(49.9)$ & .85 & & & \\
\hline Education & & & 3 & .003 & $.01-.04$ \\
\hline Secondary degree level & $64(0.9)$ & .91 & & & \\
\hline University degree level & $669(90.1)$ & .86 & & & \\
\hline Residence & & & & .11 & $0.003-2.47$ \\
\hline Rural & $77(10.5)$ & .83 & & & \\
\hline Urban & $654(89.5)$ & .87 & & & \\
\hline Country of origin & & & 8.6 & .000 & $.01-.17$ \\
\hline Burundi & $614(83.4)$ & .89 & & & \\
\hline Other Eastern African countries & $123(16.6)$ & .74 & & & \\
\hline Occupation & & & & .64 & $-.003-.05$ \\
\hline Humanitarian & $92(12.4)$ & .86 & & & \\
\hline health care worker & $643(87.6)$ & .86 & & & \\
\hline Monthly income & & & 2.72 & .017 & $.007-.07$ \\
\hline $100 \$-490 \$$ & $472(69.7)$ & .87 & & & \\
\hline$>490 \$$ & $205(30.3)$ & .83 & & & \\
\hline
\end{tabular}

Table 4. B: Clinical risk factors associated with Mean SF6DV identified by Univariate analysis among frontline and secondline workers.

\begin{tabular}{cccccc}
\hline Variable & N (\%) & Mean SF6DV & t & P-value & 95\%CI \\
\hline Chronic disease & & 3.04 & .002 & $.02-07$ \\
\hline No & $677(92.0 \%)$ & .87 & & & \\
\hline Yes & $59(8 \%)$ & .79 & & & \\
\hline Are you pregnant & & & 1.01 & .331 & $-.04-.13$ \\
\hline
\end{tabular}




\begin{tabular}{|c|c|c|c|c|c|}
\hline No & 681 & .86 & & & \\
\hline Yes & 17 & .82 & & & \\
\hline Do you have children? & & & 1.73 & .083 & $-.003-.05$ \\
\hline No & 407 & .87 & & & \\
\hline Yes & 323 & .85 & & & \\
\hline Positively tested COVID & & & 1.98 & $<.001$ & $.06-19$ \\
\hline No & $710(95.8)$ & .87 & & & \\
\hline Yes & $31(4.2)$ & .74 & & & \\
\hline Been suspected of COVID-19 & & & & $<.001$ & $.09-.16$ \\
\hline No & $599(80.9)$ & .89 & & & \\
\hline Yes & 141(19.1) & .76 & & & \\
\hline Been quarantined & & & & $<.001$ & $.08-.15$ \\
\hline No & $610(82,5)$ & .89 & & & \\
\hline Yes & $129(17.5)$ & .76 & & & \\
\hline Exposed to COVID-19 patients in the hospital & & & & $<.001$ & $.06-.11$ \\
\hline No & $511(69.1)$ & .89 & & & \\
\hline Yes & $228(30.9)$ & .80 & & & \\
\hline Exposed to COVID-19 patients in family & & & & $<.001$ & $.06-.16$ \\
\hline No & $687(92.6)$ & .87 & & & \\
\hline Yes & $55(7.4)$ & .76 & & & \\
\hline Those exposed to death from Covid-19 & & & & .026 & $.10-.23$ \\
\hline No & $711(96.0)$ & .87 & & & \\
\hline Yes & $30(4.0)$ & .70 & & & \\
\hline Shortage of PPE & & & & $<.001$ & $.03-.08$ \\
\hline No & $347(46.8)$ & .90 & & & \\
\hline Yes & $395(53.2)$ & .83 & & & \\
\hline Shortage of Medicine & & & & $<.001$ & $.06-.11$ \\
\hline No & $516(69.6)$ & .90 & & & \\
\hline Yes & $225(30.4)$ & .83 & & & \\
\hline Have you called a health care provider? & & & 2.6 & .001 & $.04-.13$ \\
\hline No & 676 & .88 & & & \\
\hline Yes & 53 & .74 & & & \\
\hline Have you had traumatic memories? & & & 6.3 & $<.001$ & $.10-.19$ \\
\hline $\mathrm{No}$ & 586 & .90 & & & \\
\hline Yes & 147 & .75 & & & \\
\hline Having depression symptom & & & 10.6 & $<.001$ & $.11-.16$ \\
\hline Not depressed & 66.6 & .91 & & & \\
\hline Depressed & 33.4 & .77 & & & \\
\hline Insomnia & & & 12.8 & $<.001$ & $.14-.24$ \\
\hline Normal sleep & $557(75.7)$ & .91 & & & \\
\hline insomnia & $179(24.3)$ & .73 & & & \\
\hline
\end{tabular}




\begin{tabular}{|c|c|c|c|c|c|}
\hline Being stressed & & & 11.3 & $<.001$ & $.10-.14$ \\
\hline Not stressed & $293(55.9)$ & .94 & & & \\
\hline Stressed & $441(44.1)$ & .82 & & & \\
\hline Destressed & & & 11.7 & $<.001$ & $.11-.17$ \\
\hline Not destressed & $492(67)$ & .91 & & & \\
\hline destressed & 242(33) & .77 & & & \\
\hline Smoking & & & & .034 & $.85-.88$ \\
\hline No change & 698(94) & .87 & & & \\
\hline Increase & $35(4)$ & .79 & & & \\
\hline Decrease & $3(2)$ & .94 & & & \\
\hline Alcohol & & & & .056 & \\
\hline no change & $478(65.1)$ & .88 & & & \\
\hline increase & $209(28.4)$ & .86 & & & \\
\hline decrease & $48(6.5)$ & .79 & & & \\
\hline
\end{tabular}

Table 5. B: Associated Factors for Mental Health Outcomes (mean QALY-SF6DV2) Identified by Multivariable Logistic Regression Analysis.

\begin{tabular}{cccccc}
\hline & $\mathbf{B}$ & $\mathbf{t}$ & \multicolumn{2}{c}{ Sig. } & \multicolumn{2}{c}{ 95\% Confidence Interval for B } \\
\hline Variable & & & .000 & .942 & 1.114 \\
\hline Constant) & 1.028 & 23.531 & .048 & -.055 & .000 \\
\hline Being female & -.028 & -1.981 & .905 & -.037 & .033 \\
\hline Being older & -.002 & -.119 & .189 & -.014 & .072 \\
\hline Married & .029 & 1.316 & .198 & -.077 & .016 \\
\hline Higher education & -.031 & -1.288 & .852 & -.036 & .044 \\
\hline Urban area & .004 & .187 & .016 & -.088 & -.009 \\
\hline Other EAC & -.048 & -2.407 & .082 & -.005 & .077 \\
\hline Health care worker & .036 & 1.740 & .728 & -.026 & .038 \\
\hline Higher monthly income & .006 & .347 & .552 & -.044 & .024 \\
\hline Working on frontline & -.010 & -.594 & .037 & -.093 & -.003 \\
\hline Having a chronic disease & -.048 & -2.093 & .485 & -.113 & .053 \\
\hline Being pregnant & -.030 & -.699 & .714 & -.034 & .049 \\
\hline Have a child & .008 & .367 & .033 & .006 & .130 \\
\hline been Tested positive covid-19 & .068 & 2.139 & .357 & -.059 & .021 \\
\hline Been Suspected of covid-19 & -.019 & -.922 & .156 & -.071 & .011 \\
\hline Been in Quarantine & -.030 & -1.420 & .755 & -.036 & .026 \\
\hline Been exposed to COVID-19 pa- & -.005 & -.313 & .844 & -.054 & .044 \\
\hline tient & -.005 & -.197 & .034 & -.135 & -.005 \\
\hline Been exposed to a family mem- \\
ber
\end{tabular}




\begin{tabular}{cccccc}
\hline Increased tobacco use & -.032 & -1.165 & .245 & -.085 & .022 \\
\hline Been depressed & -.029 & -1.613 & .107 & -.064 & .006 \\
\hline Been anxious & .015 & .840 & .401 & -.020 & .050 \\
\hline Experienced Insomnia & -.082 & -4.410 & .000 & -.118 & -.045 \\
\hline Been destressed & -.052 & -2.850 & .005 & -.088 & -.016 \\
\hline Been stressed out & -.034 & -2.145 & .032 & -.065 & -.003 \\
\hline Having fear of COVID & -.002 & -2.305 & .022 & -.005 & .000 \\
\hline
\end{tabular}

Table 6. B: Associated factors for Mental Health Outcomes (mean CORE_OM) Identified by Multivariable Logistic Regression Analysis.

\begin{tabular}{|c|c|c|c|c|c|}
\hline & $\bar{B}$ & $\mathbf{t}$ & Sig. & \multicolumn{2}{|c|}{ 95\% Confidence Interval for B } \\
\hline Variable & & & & Lower Bound & Upper Bound \\
\hline (Constant) & .894 & 25.354 & .000 & .825 & .963 \\
\hline Being female & -.007 & -.635 & .526 & -.029 & .015 \\
\hline Being older & -.011 & -.769 & .442 & -.040 & .017 \\
\hline Married & .029 & 1.629 & .104 & -.006 & .064 \\
\hline Higher ducation & .017 & .870 & .385 & -.021 & .054 \\
\hline Urban area & .028 & 1.675 & .094 & -.005 & .060 \\
\hline Other EAC & .011 & .690 & .491 & -.021 & .043 \\
\hline Health care worker & .006 & .366 & .715 & -.027 & .039 \\
\hline Higher monthly income & .018 & 1.347 & .179 & -.008 & .043 \\
\hline Working on frontline & .017 & 1.205 & .229 & -.011 & .044 \\
\hline Having a chronic disease & -.042 & -2.276 & .023 & -.079 & -.006 \\
\hline Being pregnant & -.013 & -.387 & .699 & -.080 & .054 \\
\hline Have a child & -.017 & -1.003 & .316 & -.051 & .016 \\
\hline been Tested positive covid-19 & -.013 & -.506 & .613 & -.063 & .037 \\
\hline Been Suspected of covid-19 & -.003 & -.200 & .841 & -.036 & .029 \\
\hline Been in Quarantine & -.005 & -.318 & .751 & -.039 & .028 \\
\hline $\begin{array}{l}\text { Been exposed to COVID-19 pa- } \\
\text { tient }\end{array}$ & -.030 & -2.341 & .020 & -.056 & -.005 \\
\hline $\begin{array}{l}\text { Been exposed to a family mem- } \\
\text { ber }\end{array}$ & .003 & .147 & .883 & -.037 & .043 \\
\hline Been exposed to death & -.055 & -2.067 & .039 & -.107 & -.003 \\
\hline Experienced a Shortage of PPE & .005 & .405 & .686 & -.018 & .028 \\
\hline Experienced a shortage of drug & -.009 & -.740 & .460 & -.035 & .016 \\
\hline $\begin{array}{l}\text { Having called a health care pro- } \\
\text { vider }\end{array}$ & -.001 & -.030 & .976 & -.040 & .039 \\
\hline Had traumatic memories & -.021 & -1.497 & .135 & -.048 & .006 \\
\hline Increased alcohol uptake & -.002 & -.266 & .790 & -.021 & .016 \\
\hline Increased tobacco use & -.023 & -1.064 & .288 & -.067 & .020 \\
\hline Been depressed & -.032 & -2.194 & .029 & -.060 & -.003 \\
\hline Been anxious & .004 & .242 & .809 & -.025 & .032 \\
\hline Experienced Insomnia & -.048 & -3.183 & .002 & -.077 & -.018 \\
\hline Been destressed & -.022 & -1.481 & .139 & -.051 & .007 \\
\hline Been stressed out & -.036 & -2.819 & .005 & -.061 & -.011 \\
\hline Having fear of COVID & -.004 & -4.445 & .000 & -.005 & -.002 \\
\hline
\end{tabular}




\section{REFERENCE.}

1. Lai J, Ma S, Wang Y, Cai Z, Hu J, Wei N, et al. Factors Associated With Mental Health Outcomes Among Health Care Workers Exposed to Coronavirus Disease 2019. JAMA Netw Open. 2020;3(3):e203976.

2. The Lancet. COVID-19: protecting health-care workers. Lancet [Internet]. 2020;395(10228):922. Available from: http://dx.doi.org/10.1016/S0140-6736(20)30644-9

3. Serralta FB, Zibetti MR, Evans C. Psychological distress of university workers during COVID-19 pandemic in Brazil. Int J Environ Res Public Health. 2020;17(22):1-18.

4. Than HM, Nong VM, Nguyen CT, Dong KP, Ngo HT, Doan TT, et al. Mental health and health-related quality-of-life outcomes among frontline health workers during the peak of the covid-19 outbreak in Vietnam: A cross-sectional study. Risk Manag Healthc Policy. 2020;13:2927-36.

5. Rossi R, Socci V, Pacitti F, Di Lorenzo G, Di Marco A, Siracusano A, et al. Mental Health Outcomes Among Frontline and Second-Line Health Care Workers During the Coronavirus Disease 2019 (COVID-19) Pandemic in Italy. JAMA Netw Open. 2020;3(5):e2010185.

6. American Association for Public Opinion Research (AAPOR). Measurements, Records, or Other Data That Can Be Used Alone or in Combination To Distinguish or Trace an Individual'S Identity and (. 2015;1-7)

7. Unless R, Act P, Rose W, If T, Rose W. This is a repository copy of The estimation of a preference-based measure of health from White Rose Research Online URL for this paper : Article : Brazier, J . E ., Roberts, J . and Deverill , M . ( 2002 ) The estimation of a preference-based measure of. 2002;

8. Falkenström F, Kumar M, Zahid A, Kuria M, Othieno C. Factor analysis of the Clinical Outcomes in Routine Evaluation - Outcome Measures (CORE-OM) in a Kenyan sample. BMC Psychol. 2018;6(1):1-9.

9. Ahorsu DK, Lin CY, Imani V, Saffari M, Griffiths MD, Pakpour AH. Fear of COVID-19 Scale. Int J Ment Health Addict. 2020;103.

10. Huang F, Yang Z, Wang Y, Zhang W, Lin Y, Zeng LC, et al. Health-Related Quality of Life and Influencing Factors of Pediatric Medical Staff During the COVID-19 Outbreak. Front Public Heal. 2020;8(October):1-7)

11. Ahmed SAKS, Ajisola M, Azeem K, Bakibinga P, Chen Y-F, Choudhury NN, et al. Impact of the societal response to COVID-19 on access to healthcare for non-COVID-19 health issues in slum communities of Bangladesh, Kenya, Nigeria and Pakistan: results of pre-COVID and COVID-19 lockdown stakeholder engagements. BMJ Glob Heal. 2020;5(8):e003042.

12. Bommelé J, Hopman P, Walters BH, Geboers C, Croes E, Fong GT, et al. The double-edged relationship between COVID-19 stress and smoking: Implications for smoking cessation. Tob Induc Dis. 2020;18(April):1-5.

13. Biddle N, Edwards A Ben, Gray M. Alcohol consumption during the COVID- 19 period : May 2020 ANU Centre for Social Research and Methods. 2020;(May). 